\title{
MELHORAMENTO GENÉTICO DA BANANEIRA: ESTRATÉGIAS E TECNOLOGIAS DISPONÍVEIS ${ }^{1}$
}

\author{
SEBASTIÃO DE OLIVEIRA E SILVA², EDSON PERITO AMORIM ${ }^{3}$, \\ JANAY ALMEIDA DOS SANTOS-SEREJO ${ }^{4}$, CLÁUDIA FORTES FERREIRA ${ }^{5}$, \\ MIGUEL ANGEL DITA RODRIGUEZ
}

RESUMO- A banana cultivada 107 países, em uma área de 4,1 milhões de hectares e produção de 95 milhões de toneladas, é segunda fruta mais produzida do mundo. A bananeira é atacada por vírus (CMV e BSV), fungos (Sigatoka amarela e negra, mal-do-Panamá), bactéria (Moko), nematoide e insetos (Broca do rizoma). No entanto, por meio do melhoramento genético é possível obter resistência a maioria das pragas e doenças. O centro de origem de grande parte do germoplasma de Musa spp. é o Continente Asiático, onde são encontradas bananeiras diploides, triploides tetraploides, com genomas de Musa acuminta e M. balbisiana. No melhoramento de banana, feito principalmente para resistência às doenças, são usados os seguintes métodos: introdução e seleção de clones; hibridação (cruzamentos de diploides com diploides, triploides com diploides e diploides com tetraploides); duplicação de cromossomos; mutação e transgenia. Os métodos que envolvem hibridação, embora sejam os mais usados, apresentam limitações como a partenocarpia, a esterilidade; o número variável de ploidia e a baixa produção de sementes. Todo material produzido no programa, é depois avaliado nas regiões produtoras de banana. Atualmente novas técnicas de melhoramento, baseadas em informações genéticas de Musa spp. estão sendo incrementadas.

Termos para indexação: hibridação, duplicação de cromossomos, mutação e transgenia.

\section{GENETIC IMPROVEMENT OF BANANA: STRATEGIES AND AVAILABLE TECHNOLOGIES}

\begin{abstract}
Bananas are cultivated in more than 107 countries in an area of 4.1 million hectares with a production of 95 million tons and considered the second most produced fruit worldwide. Bananas are attacked by viruses (CMV and BSV), fungi (Yellow and Black Sigatoka and Fusarium), bacteria (Moko), nematodes and insects (Weevils). However, through genetic breeding, it is possible to achieve resistance to most pests and diseases. The center of origin of most of Musa spp. germplasm is the Asian Continent, where diploid, triploid, Tetraploid with genome Musa acuminata and Musa balbisiana bananas are found. In banana breeding, especially for disease resistance, the following methods are employed: introduction and selection of clones; hybridization (crosses between diploids and diploids, triploids and diploids and diploids with tetraploids); chromosome duplication; mutation and transgenic. Methods involving hybridization, however, the method mostly used, is limited by pathernocarpy, sterility, variable number of ploidy levels and low seed production. All varieties produced by the program are then evaluated in banana producing regions in Brazil. Recently new breeding techniques based on genetic information on Musa ssp. are being incremented.
\end{abstract}

Index terms: hybridization, chromosome duplication, mutation and transgenic.

\footnotetext{
${ }_{1}^{1}$ (Trabalho 315-13). Recebido em: 07-06-2013. Aceito para publicação em: 11-09-2013.

${ }^{2}$ Professor Visitante da Universidade Federal do Recôncavo da Bahia (URFB). Dr. em Genética e Melhoramento de Plantas. E-mail: ssilva3000@gmail.com

${ }^{3}$ Pesquisador da Embrapa Mandioca e Fruticultura. Dr. em Genética e Melhoramento de Plantas. E-mail: edson@cnpmf.embrapa.br; ${ }^{4}$ Pesquisadora da Embrapa Mandioca e Fruticultura. Dra. em Genética e Melhoramento de Plantas. E-mail: janay@cnpmf.embrapa.br; claudia.ferreira@embrapa.br;

${ }^{5}$ Researcher at Bioversity International, Location Costa Rica, Industry Nonprofit Organization. m.dita@cgiar.org
} 


\section{INTRODUÇÃO}

A banana ocupa a segunda posição na produção mundial de frutas e juntamente com o arroz, o trigo e o milho são consideradas como as fontes alimentares mais importantes do mundo (PERRIER et al., 2011). Cultivado em 107 países, a cultura apresenta uma área de plantio estimada em 4,1 milhões de hectares e uma produção de 95 milhões de toneladas. O Brasil é o quinto maior produtor mundial de banana, com produção de aproximadamente 7,0 milhões de toneladas, em uma área de 487 mil hectares. Estima-se que a produção dessa fruta empregue, direta e indiretamente, 960 mil pessoas no mundo (FAO, 2012).

Apesar da importância da bananicultura, poucas cultivares estão disponíveis para exploração comercial com potencial agronômico, tolerantes às pragas e doenças, e que apresentem frutos com boas características de mercado.

A bananeira é atacada por diversos fitopatógenos. Os fungos de maior importância são os agentes causais da Sigatoka-amarela (Mycosphaerella musicola, Leach), Sigatoka-negra (Mycosphaerella fijiensis, Morelet) e mal-do-Panamá (Fusarium oxysporum f. sp. cubense). O Moko da bananeira, causado pela bactéria Ralstonia solanacearum (raça 2), tem limitado a produção em alguns estados brasileiros. As principais viroses presentes no Brasil são o Banana Streak Virus (BSV) e o Cucumber Mosaic Virus (CMV) (BRIOSO et al., 2000). O Banana Bunchy Top Virus (BBTV) e Banana Bract Mosaic Virus (BBRMV) ainda não foram relatados no Brasil. O nematoide que tem causado maiores danos à bananicultura é o Radopholus similis, e a broca-do-rizoma (Cosmopolites sordidus) é o inseto-praga mais importante.

As cultivares mais usadas pelos agricultores (Prata, Pacovan, Maçã, Grande Naine e Terra) são muito suscetíveis à Sigatoka-negra e, à exceção da Terra e Maçã, são também suscetíveis à Sigatoka-amarela. Com relação ao mal-do-Panamá, a 'Grande Naine' e a 'Terra' são resistentes, a 'Maçã' é altamente suscetível e as demais cultivares são medianamente suscetíveis.

As medidas de controle químico utilizadas por grandes empresas não são válidas ou são pouco aplicáveis para os pequenos agricultores, que representam a grande maioria dos produtores brasileiros de banana. O uso de cultivares resistentes, seja pela seleção dentro dos recursos genéticos existentes, seja pela geração de novas cultivares por hibridação, é considerado a medida de controle mais eficiente (AMORIM et al., 2011). Uma variedade melhorada pode induzir um aumento de produtividade e um menor custo de produção, em função do reduzido emprego de defensivos agrícolas e redução de gastos com o manejo da cultura, aumentando, consequentemente, a renda líquida do produtor.

A Embrapa iniciou um programa de melhoramento de bananeira (PMGB) em 1976, a partir da criação de sua coleção de germoplasma. Este programa utiliza diferentes estratégias para o desenvolvimento de cultivares: 1) Cruzamento de triploides com diploides selvagens ou melhorados; 2) Cruzamento de tetraploides com diploides selvagens ou melhorados; 3) Duplicação de cromossomos de diploides superiores; e 4) Indução de mutação. O PMGB da Embrapa desenvolveu as seguintes cultivares por meio de hibridação: BRS Caprichosa, BRS Garantida, BRS Japira, BRS Pacovan Ken, BRS Preciosa, BRS Princesa, BRS Tropical, BRS Vitória, BRS Pioneira e BRS Platina. Além dessas cultivares, foram recomendadas a FHIA 01 (BRS Maravilha), BRS Pelipita e BRS Thap Maeo (Mysore) (SILVA et al., 2011a). As cultivares mais utilizadas pelos agricultores brasileiros, Prata-Anã e Pacovan, também foram recomendadas pela Embrapa a partir da seleção de genótipos em sua coleção de germoplasma (ALVES et al., 1985).

As dificuldades da hibridação na maioria das variedades têm levado ao desenvolvimento de novas técnicas de melhoramento de bananeira para a criação de cultivares resistentes às doenças, as quais complementam e dão suporte às convencionais. Entre elas, podem-se citar a hibridação somática, a fertilização in vitro, a mutação, a duplicação de cromossomos e a transformação genética (SILVA et al., 2005; SILVA et al., 2011a).

\section{Origem e evolução da bananeira}

O centro de origem da maior parte do germoplasma de banana está localizado no continente asiático. Outros centros secundários ocorreram na África Oriental, em algumas ilhas do Pacífico e uma considerável diversidade genética, na África Ocidental (CHAMPION, 1967). As cultivares encontradas nestas regiões evoluíram-se de espécies selvagens e apresentam três níveis cromossômicos, existindo diploides com 22 cromossomos (2x), triploides com $33(3 \mathrm{x})$ e tetraploides com 44 cromossomos $(4 \mathrm{x})$, que são múltiplos do número básico $(\mathrm{n}=11)$, sendo que a origem de triploides a partir de diploides e de tetraploides a partir dos triploides é facilmente constatada por meio de cruzamentos experimentais (SHEPHERD, 1984).

Cruzamentos interespecíficos entre M. acumi- 
nata Colla (genoma $\mathrm{A}, 2 \mathrm{n}=2 \mathrm{x}=22$ ) e $M$. balbisiana Colla (genoma $\mathrm{B}, 2 \mathrm{n}=2 \mathrm{x}=22$ ) deram origem à maioria dos genótipos de bananeiras atualmente em uso para alimentação. As plantas geradas destes cruzamentos apresentam características das duas espécies (SIMMONDS, 1973). Esses híbridos podem apresentar diversas ploidias, verificando-se casos com 20;22; 33; 44; 55; 77 e 88, podendo encontrar, inclusive, vários tipos de aneuploidias. A espécie M. acuminata é seminífera, com diversas subespécies, enquanto M. balbisiana, também seminífera, é mais vigorosa que a anterior.

Um estudo desenvolvido por Cheesman (1948) explicou a participação das espécies $M$. acuminata e M. balbisiana na origem das bananeiras com frutos comestíveis. Simmonds e Shepherd (1955) comprovaram esses resultados por meio de estudos taxonômicos baseados em quinze características morfológicas das duas espécies, embora não descartassem a possibilidade da contribuição, em pequena escala, de outras espécies, como a $M$. schyzocarpa (genoma $\mathrm{S}, 2 \mathrm{n}=2 \mathrm{x}=22$ ), oriunda da Nova Guiné, e Australimusa (genoma T, 2n=2x=20). O cruzamento entre espécies e subespécies pode ter levado ao aparecimento da partenocarpia, uma característica selecionada pelo homem em conjunto com a esterilidade, levando assim à fixação de genótipos estéreis com frutos comestíveis. Os estudos desses autores levaram à constatação dos seguintes grupos genômicos: diploides (AA e AB), triploides (AAA, $\mathrm{AAB}$ e ABB) e tetraploides (AAAA, AAAB, AABB e ABBB), sendo esta a classificação adotada em todo o mundo (Figura 1).

Além dos grupos genômicos, foi estabelecido o uso do termo subgrupo, para denominar um complexo de cultivares, originárias, por meio de mutações de uma única cultivar original (SHEPHERD et al., 1984), como no caso do grupo AAA, subgrupo Cavendish e grupo AAB, subgrupos Prata e Terra, no Brasil. A diferença entre um diploide e um tetraploide pode ser observada na Figura 2.

Os genótipos com a coloração rosada nas bainhas, pecíolos e nervura principal, aproximam-se mais da espécie parental M. acuminata, que apresenta ainda manchas escuras distribuídas no pseudocaule (STOVER; SIMMONDS, 1987). Para esses autores, as cultivares herdaram de $M$. balbisiana características semelhantes às espécies silvestres, com pouca pigmentação, apresentando um aspecto pálido nas regiões mais elevadas do pseudocaule e do pecíolo.

A constituição genômica de acessos de bananeira, estimada com base em características morfológicas e número de cromossomos, tem sido confirmada mediante técnicas moleculares e de citogenética (OSUJI et al., 1997; D'HONT et al., 2000; DOLEZEL; BARTOS, 200ㅍ; PERRIER et al., 2009). A hibridização genômica in situ (GISH) permite diferenciar cromossomos dos quatro genomas de banana conhecidos (A, B, S e T) sendo, portanto, uma ferramenta para a identificação da origem de cromossomos e podendo ser utilizada para caracterizar cultivares e híbridos produzidos em programas de melhoramento (D'HONT et al., 2000). A técnica de BAC-FISH de alta resolução também vem sendo explorada de forma a aumentar o potencial de informações a serem usadas nos programas de melhoramento da bananeira (CAPDEVILLE et al., 2009).

\section{Estratégias para o desenvolvimento de novas cultivares}

Desde 1920, os programas de melhoramento de bananeira têm focado no desenvolvimento de cultivares com resistência a pragas e doenças. Além disso, trabalhos envolvendo aspectos socioeconômicos ligados aos sistemas de produção e à suscetibilidade natural das cultivares atualmente em uso pelos agricultores vêm sendo realizados. De maneira geral, buscam-se genótipos com resistência a doença, precocidade de produção, elevada produtividade, porte baixo, bom sistema radicular, eficiência no uso de água e nutrientes, e qualidade dos frutos (tamanho, forma, sabor e aroma) (PUA et al.,2003; Silva et al., 2011a).

Atualmente, com o advento das modernas ferramentas da biologia molecular e com a cultura de tecidos, novas possibilidades têm permitido ampliar os estudos genéticos em bananeira, com destaque para a hibridação somática, a seleção assistida e a engenharia genética (KOVACS et al., 2012; PILLAY et al., 2012). Neste contexto, a introdução de genes exóticos ou mesmo o uso da cisgenia (REMY et al., 2007) poderá conduzir ao desenvolvimento de genótipos, por exemplo, resistentes a viroses ou com maior vida de prateleira. Além disso, aventa-se a possiblidade de desenvolver bananeiras com a função de servir como veículo para vacinas em países subdesenvolvidos (SALA et al., 2003). Cabe destacar, também, a finalização do sequenciamento do genoma de bananeira, realizado pelo Global Musa Genomics Consortium com a participação da Embrapa (D'HONT et al., 2012). 


\section{Dificuldades do melhoramento genético por hibridação}

De maneira geral, as bananeiras comestíveis são partenocárpicas e estéreis, características que dificultam o melhoramento genético. Durante sua evolução, genótipos com alta ploidia foram selecionados pelos agricultores,em especial devido ao seu vigor e rendimento elevados (KHAYAT; ORTIZ, 2011). Desta forma, genótipos triploides e tetraploides passaram a dominar as áreas de produção de banana. Especificamente, em se tratando de triploides, as cultivares do subgrupo Cavendish passaram a ser as mais cultivadas no mercado internacional, enquanto no Brasil, há predominância de cultivares do tipo Prata - em especial 'Prata-Anã' e 'Pacovan' (AMORIM et al., 2011).

As progênies obtidas a partir de cruzamentos entre genótipos de bananeira apresentam tamanho pequeno e são compostas por um número variável de ploidias, inclusive aneuploides. Esse fato dificulta o melhoramento genético e impõe barreiras ao desenvolvimento de novas cultivares.

A produção de sementes oriundas de cruzamentos é possível, independentemente da ploidia, sendo maior entre diploides, seguido, respectivamente, de tetraploides e triploides. Os cruzamentos são possíveis mesmo envolvendo cultivares consideradas estéreis, assim, Aguilar Morán (2011) obteve sementes a partir da polinização de 20.000 cachos de cultivares do subgrupo Cavendish (Grande Naine e Williams) com pólen de 10 diploides. Como resultado deste esforço, foram obtidas 200 sementes com 40 embriões, e 20 híbridos tetraploides foram recuperados, os quais foram cruzados com o diploide SH3142, originando dois híbridos triploides semelhantes às cultivares originais.

Em cultivares triploides, o número de frutos por cacho pode variar de 100 a 250 , e o número de óvulos, de 300 a 600 por fruto. Na ausência de gametas estéreis, o potencial de produção de sementes pode chegar a 150.000 sementes por cacho (BAKRY et al., 2009). Considerando o cruzamento entre diploides com genomas A e B, a probabilidade de se obter um híbrido $\mathrm{AB}$ fértil é muito baixa, devido, em parte, à parcial homologia entre os cromossomos de acuminata e balbisiana. Por outro lado, em cruzamentos envolvendo diploides AA, observa-se ampla variação quanto à fertilidade masculina (pólen) e feminina (sementes). Nessas condições, obtêm-se até 5.000 sementes por cacho.

De maneira geral, a maioria das sementes obtidas por meio dos cruzamentos entre diploides e triploides ou tetraploides apresenta alguma anomalia, principalmente a ausência de embrião e/ou endosperma. Além disso, a taxa de germinação das sementes obtidas é em torno de $20 \%$ em condições de casa de vegetação. Este fato explica o uso rotineiro da técnica de resgate de embriões, que pode elevar a germinação para próximo de 85\% (BAKRY; HORRY, 1992).

Anormalidades na meiose também são muito frequentes em diploides e triploides,em especial associadas com o pareamento cromossômico. Em tetraploides, a formação de gametas $2 n$ ou $4 n$ é frequentemente relatada na literatura. Todas essas irregularidades dificultam a previsão da segregação observada nas progênies.

\section{Principais métodos de melhoramento}

A bananeira apresenta particularidades que direcionam o melhorista na utilização de diferentes estratégias de melhoramento. Considerando os problemas de esterilidade, notáveis progressos foram obtidos nestes últimos 20 anos de pesquisas com Musa em nível mundial. Basicamente, duas estratégias são priorizadas para desenvolver novas cultivares de bananeira; a primeira está associada com o desenvolvimento de tetraploides a partir da hibridação entre $3 x$ e $2 x$; e a segunda envolve a geração de triploides secundários a partir do cruzamento entre $4 x$ e $2 x$. Adicionalmente, a introdução e a seleção de clones têm sido também utilizadas como alternativa.

\section{Introdução e seleção de clones}

A introdução de germoplasma exótico por meio de coletas e intercâmbio pode ser considerada como um método de melhoramento, uma vez que disponibiliza variabilidade genética para a seleção de genótipos/clones superiores com potencial de uso pelos agricultores (ALLARD, 1999).

Uma série de clones foi selecionada nas últimas décadas a partir da introdução e de testes de genótipos em novas áreas, entre os quais as cultivares Pacovan, mutante de 'Prata Comum', Prata-Anã, mutante da 'Branca' e Mysore selecionadas pelo programa de melhoramento da Embrapa. (ALVES et al., 1985).

Em países como Israel, África do Sul, Austrália e Espanha, a produção de nova variedade de banana é baseada na seleção de clones superiores em áreas de produtores (LICHTEMBERG, 1997; KHAYAT el al., 1998). 


\section{Melhoramento por hibridação}

\section{Estratégia $3 x / 2 x$ : desenvolvimento de tetraploides}

As variedades triploides apresentam fertilidade residual que permite a obtenção de sementes em cruzamentos com diploides (BAKRY; HORRY, 1992). A particularidade deste cruzamento está no fato de que os alelos da planta-mãe podem não segregar e, portanto, as características maternas são mantidas, resultando em híbridos tetraploides. De acordo com Menendez e Shepherd (1975), é possível acrescentar um conjunto de cromossomos de um diploide para transferir características de resistência às doenças ao novo híbrido.

Após o cruzamento $3 x / 2 x$, é possível obter-se híbridos com 22 e 33 cromossomos devido à meiose desequilibrada (sacos embrionários com 11 a 22 cromossomos +11 cromossomos do pólen haploide), bem como híbridos com 44 cromossomos $(33+11)$ ou mesmo 77 cromossomos (duas vezes $33+11$ ). Mesmo com diferentes possibilidades de segregação, apenas os híbridos tetraploides (44 cromossomos) apresentam características agronômicas que possibilitem sua adoção pelos agricultores, entre as quais sabor e aroma. Além disso, o híbrido resultante do cruzamento $3 x / 2 x$ possui o genoma completo do parental feminino e características do doador de pólen, uma vez que $25 \%$ dos alelos estão associados com o pai e $75 \%$ serão herdados da planta-mãe. Para o sucesso desta estratégia, a seleção do parental masculino (diploide) é de suma importância, sendo que o mesmo deve transferir características como a resistência a doenças à progênie.

De acordo com Bakry et al. (2009), o híbrido $A A A B$, resultado do cruzamento entre um $A A B$ e um AA, pode apresentar sintomas do vírus BSV (Banana Streak Virus) em função da ativação da sequência viral inserida no genoma B. Além disso, a baixa fertilidade dos triploides faz com que pequenas progênies sejam obtidas, e um considerável número de cruzamentos deva ser realizado, visando a gerar híbridos tetraploides promissores (resistentes a doenças, produtivos e com boas características de sabor e aroma).

Cheesman e Dodds (1942) e Shepherd (1960) foram os responsáveis por uma série de trabalhos, visando a quantificar a fertilidade de diferentes triploides. De acordo com esses autores, as cultivares do subgrupo Cavendish são quase totalmente estéreis, enquanto as mais férteis pertenceram ao grupo $\mathrm{ABB}$, com comportamento intermediário para genótipos do grupo AAB. Outra importante observação diz respeito à quantidade de sementes obtidas: $M u s a$ balbisiana $<$ Musa acuminata. Em experimento realizado por Oselebe et al. (2006), visando a quantificar a variação na ploidia em cruzamentos de $M u s a$, os autores verificaram que $99,7 \%$ dos indivíduos de uma progênie oriunda do cruzamento $2 x / 2 x$ apresentam $2 n=22$. Já quando se utiliza um diploide como parental feminino e um tetraploide como masculino, em 96,2\% da progênie, observam-se genótipos diploides. Por outro lado, utilizando-se do tetraploide como fêmea, observa-se que $94,1 \%$ da progênie possui genoma triploide.

Outro método para desenvolver tetraploides foi proposto por Rowe e Rosales (1995) a partir de triploides primários e secundários, com o uso de três diferentes diploides: $3 x$ (primário) x $2 x$ (a) $\mathrm{P} 4 x$ (primário) x $2 x$ (b) $\mathrm{P} 3 x$ (secundário) x $2 x(\mathrm{c}) \mathrm{P} 4 x$ (secundário). O triploide SH3386 foi obtido pelo programa de melhoramento genético de banana da Fundação Hondurenha de Investigação Agrícola (FHIA), utilizando esta metodologia. Este sistema mostra-se eficiente no melhoramento de híbridos com genoma $\mathrm{ABB}$, porém não é recomendado para bananas de sobremesa e plátanos, devido à perda de características agronômicas desejáveis durante o processo.

Especificamente em se tratando de plátanos, a literatura indica que a probabilidade de obtenção de sementes em cruzamentos envolvendo este germoplasma é muito baixa (SHEPHERD, 1960). No entanto, cruzamentos desenvolvidos a partir de plátanos dos tipos horn e french produziram sementes, e híbridos tetraploides foram recuperados (ROWE; ROSALES, 1996; VUYLSTEKE et al.,1995; TOMEKPE et al., 1995; AMORIM, 2012).

A Embrapa já desenvolveu uma série de híbridos tetraploides a partir da hibridação $3 x / 2 x$; em sua grande maioria resistente às principais doenças da bananeira (sigatokas amarela e negra e mal-do-panamá) (SILVA et al., 2011a) Outros programas, a exemplo do desenvolvido em Honduras (FHIA), também possuem uma série de híbridos tetraploides.

\section{Estratégia $2 x / 2 x$ : desenvolvimento de di- ploides melhorados}

A escolha do parental masculino para hibridação é um dos pontos mais relevantes no melhoramento da bananeira. Este fato está associado ao alto grau de homogeneidade dos gametas femininos após a meiose I, em especial na restituição da primeira divisão (SCHIFINO-WITTMANN; DALL'AGNOL, 2001).

A importância do pré-melhoramento de diploides está no fato de que a grande maioria das 
características agronômicas de interesse (ex.: partenocarpia, número de pencas, frutos compridos, cachos bem formados e resistência a doenças) encontra-se dispersa em um grande número de diploides selvagens, fazendo-se necessários a hibridação e o desenvolvimento de diploides melhorados (SILVA et al., 2011b).

Basicamente são utilizadas duas estratégias para o desenvolvimento de diploides melhorados: 1) $2 x / 2 x$ P $2 x$, em que se realiza a hibridação entre diploides selvagens, entre diploides selvagens e cultivados, e somente entre cultivados; 2) $3 x / 2 x P$ $4 x$ e $2 x$ (derivado), que depois de obtidos são intercruzados [ $2 x$ (derivado 1$)$ x $2 x$ (derivado 2$)] P 2 x$ melhorado (TOMEKPE et al., 1995). Segundo Horry et al. (1993), outra estratégia que pode ser utilizada é o desenvolvimento de linhas puras com o posterior intercruzamento entre elas.

Além do genoma AA, deve-se fazer uso de outras espécies da sessão Eumusa e Rhodochlamys, por meio de esquemas de retrocruzamentos As outras espécies a serem consideradas são: $M$. flaviflora Cheesman, M. basjoo Sieb, M. itinerans Cheesman, M. flavicarpa, M. sikkimensis Kurz e M. cheesmani Cheesman (sessão Eumusa) e M. ornata Roxb, $M$. rosea Baker, M. rubra Wall, M. laterita Cheesman e M. sanguinea Hook (sessão Rhodochlamys) (SUBBARAYA et al., 2011).

Alguns programas de melhoramento têm gerado diploides melhorados com elevado número de frutos, porte baixo, resistentes às sigatokas amarela e negra, mal-do-panamá e nematoides (ROWE; ROSALES, 1995; SHEPHERD, 1974;, VUYLSTEKE et al., 1993; TOMEKPE et al., 1995; HORRY et al.,1993).

O programa de melhoramento genético de bananeira da Embrapa utiliza 39 diploides melhorados (DM) como parentais masculinos, visando ao desenvolvimento de híbridos triploides e tetraploides. Nessa coleção, existem diploides de primeira geração (hibridação entre dois diploides selvagens) e de segunda geração (hibridação entre diploides melhorados). Esses DMs são resistentes à Sigatoka-amarela e ao mal-do-panamá. Muitos mostram-se também resistentes à Sigatoka-negra e a nematoides (SILVA et al., 2011b).

\section{triploides}

\section{Estratégia para o desenvolvimento de}

Para o desenvolvimento de triploides, basicamente são utilizadas duas estratégias de hibridação: a) cruzamento entre diploides $(2 x / 2 x)$; e b) hibridação $4 x / 2 x$.

Em se tratando especificamente do esquema $2 x / 2 x$, duas metodologias são adotadas: 1) produção de triploides AAA a partir de diploides AA; e 2) produção de triploides $\mathrm{AAB}$ a partir de diploides $\mathrm{AB}$.

Mesmo considerando a existência de cultivares AAA, poucas evidências experimentais demonstram a forma de obtenção desse germoplasma (SILVA et al., 2001). Shepherd (1976) relatou a obtenção de sementes triploides do cruzamento envolvendo diploides da subespécie Banksii e a cultivar Paka. Ainda, segundo o autor, os cachos foram superiores aos dos diploides, porém sem valor comercial. Cabe destacar que a obtenção de triploides a partir do esquema $2 x / 2 x$ mostra-se como um evento raro e de difícil observação, e que existem poucos diploides capazes de produzir embriões triploides (DANTAS et al., 1997).

A produção de triploides $\mathrm{AAB}$ a partir de diploides $A B$ vem do princípio de que cultivares $\mathrm{AAB} / \mathrm{ABB}$ devem ter evoluído a partir da fertilização de óvulos de híbridos $\mathrm{AB}$ por pólen A ou B. Alguns autores relatam que os híbridos artificiais obtidos por meio desta estratégia se mostraram altamente estéreis devido a falhas no pareamento cromossômico durante a meiose (DODDS, 1945; DODDS; PITTENDRIGH, 1946; DODDS; SIMMONDS, 1946).

A Embrapa realizou um estudo visando a obter informações sobre a fertilidade feminina de híbridos $\mathrm{AB}$, assim como identificar híbridos $\mathrm{AB}$ com potencial para desenvolver triploides AAB (SHEPHERD et al., 1990). A hipótese inicial aventava a possibilidade da obtenção de sementes triploides em mistura com pentaploides; no entanto, não foram observados triploides. Foram obtidos híbridos AB com alta capacidade de produzir diploides e aneuploides por retrocruzamentos. Somente uma exceção foi observada, já que um híbrido da cultivar Figo apresentou pequena quantidade de sementes diploides após a polinização com o pólen A.

A estratégia envolvendo o cruzamento entre tetraploides e diploides parece ser a mais viável para a obtenção de cultivares triploides e vem sendo explorada pela Embrapa. O princípio está no fato de se utilizar cultivares tetraploides com boas características agronômicas e boa qualidade de fruto como parentais femininos e diploides, tanto melhorados quanto selvagens, como parentais masculinos. De 
acordo com trabalhos de Oselebe et al. (2006), a probabilidade de se obter genótipos triploides utilizando o esquema $4 x / 2 x$ é de aproximadamente $94 \%$, implicando maior eficiência na hibridação.

\section{Produção de triploides secundários por meio da duplicação de cromossomos de diploides}

Uma estratégia bastante promissora para o desenvolvimento de triploides secundários passa pela indução da duplicação de cromossomos de diploides por meio de agentes mutagênicos, tais como a colchicina ou a orizalina (COSTA et al., 2011).

A duplicação de cromossomos permite a criação de triploides secundários $\mathrm{AAA} / \mathrm{AAB}$ por meio da duplicação in vitro de diploides $\mathrm{AA} / \mathrm{BB}$ e posterior cruzamento com diploides melhorados (BAKRY et al., 2007).

O CIRAD iniciou, em 1993, seus trabalhos com duplicação de cromossomos por meio do cruzamento entre o diploide Calcutta 4 com quatro diploides duplicados (AAAA). Foram obtidos 347 híbridos, com uma proporção de $98 \%$ de triploides secundários recuperados. Em outro trabalho, o cruzamento entre BB [Pisang Klutuk Wulung] $\times$ AAAA [diploide duplicado IDN110] resultou em 227 híbridos AAB. Esses resultados permitem inferir que os diploides duplicados produzem, na maioria das vezes, gametas poliploides contendo exatos 22 cromossomos, fato que justifica o sucesso da metodologia (BAKRY et al., 2009).

A Embrapa iniciou trabalhos visando a duplicar cromossomos de diploides e possui uma dezena de tetraploides AAAA em campo, que estão sendo avaliados para uma série de características agronômicas de interesse, entre as quais a altura de planta, o número de frutos por cacho, a fertilidade masculina (presença de pólen) e feminina (presença de sementes). Esses tetraploides estão sendo cruzados com diploides AA, visando a desenvolver triploides secundários. Um grande número de sementes tem sido obtido nesses cruzamentos, cuja ploidia vem sendo avaliada por meio da citometria de fluxo e contagem cromossômica (Morais-Lino et al., 2011, Amaral et al., 2012).

A duplicação de cromossomos tem como principais vantagens: 1) a combinação genética selecionada em nível diploide é mantida em sua totalidade ou parcialmente nos híbridos triploides secundários; 2) os híbridos obtidos apresentam esterilidade; 3) a possibilidade de se utilizar diploides selvagens como parentais masculinos permite a obtenção de um grande número de sementes; 4) a introdução de resistência a doença por meio do cruzamento com diploide melhorado e, consequentemente, a avaliação de uma progênie triploide numerosa. O grande benefício dessa metodologia está no fato de permitir a associação entre as características agronômicas dos parentais diploides, assim como de permitir a maximização da heterose na progênie triploide.

\section{Melhoramento por meio da indução de mutação}

As mutações são mudanças herdáveis na sequência do DNA e que não são derivadas da recombinação genética e/ou segregação (VAN HARTEN, 1998), e representam a base genética das variações. Essas mutações servem como ferramenta aos programas de melhoramento genético, pois levam à produção de novas formas alélicas, que podem conferir novas características agronômicas, ampliando a base genética dos recursos disponíveis para o melhoramento (Ramalho et al., 2012). As mutações naturais ocorrem em taxas muito baixas, o que limita a identificação de mutantes. No entanto, algumas substâncias químicas podem ser utilizadas para aumentar as frequências de mutações e variações, a partir das quais mutantes de interesse agronômico podem ser selecionados (PREDIERI, 2001).

Os principais agentes mutagênicos podem ser divididos em químicos: etil-nitroso-ureia (ENH), metil-nitroso-ureia (MNH), azida sódica (SA), etilmetanossulfonato (EMS), dietilsulfato, e físicos: raios $\mathrm{X}$, raios gama, nêutrons rápidos, ultravioleta $\mathrm{e}$ raios laser (JAIN, 2002).

$\mathrm{O}$ uso de agentes mutagênicos para a obtenção de variabilidade tem sido amplamente empregado no melhoramento vegetal em função de sua capacidade de alterar uma ou poucas características de cultivares bem estabelecidas (BROERTJES; HARTEN, 1988). Esta característica pode ser particularmente importante para o gênero Musa, onde a reprodução assexuada tende a reduzir a variabilidade genética (NOVAK et al., 1986). Uma vez encontrado um mutante com características de interesse, este é propagado vegetativamente, sem que seja alterada a combinação dos alelos (BRUCKNER, 1999).

A redução da altura da planta é uma das características mutantes mais frequentes em Musa spp., quando se utiliza a indução de mutação (NOVAK et al., 1990; CÔTE et al., 1993; ISRAELI et al., 1995; TANG ; HWANG, 1998; NEWBURY et al., 2000; TANG; TAI, 2001; PESTANA et al., 2011a/b; AMORIM et al., 2012).

Com relação ao uso de mutantes resistentes à doença, vale ressaltar o trabalho que vem sendo conduzido em Taiwan, para resistência ao mal-do- 
-panamá, onde foram obtidas cultivares Cavendish resistentes à raça 4 do Fusarium (HWANG, 2004).

Apesar da eficiência do método de mutação, apenas três cultivares de bananeira foram desenvolvidas por meio de raios gama. A primeira, a 'Klue Hom Thong KU1', que apresenta elevado peso de cacho, a 'Novaria' com ciclo precoce e qualidade alta dos frutos, e a 'Al-Beely' com alta produtividade (FAO/IAEA, 2012).

\section{Avaliação em campo e seleção de genótipos superiores}

O principal objetivo dos ensaios de campo é avaliar e validar os genótipos de interesse quanto às suas características agronômicas e produtivas. $\mathrm{O}$ ideal é a formação de uma ampla rede de avaliação, considerando ambientes contrastantes, condições de solo, incidência de doenças e clima.

Em bananeira, a primeira etapa de seleção é realizada para caracteres que apresentam alta herdabilidade, uma vez que está restrita a apenas um local e com um número reduzido de plantas. $\mathrm{Na}$ Embrapa, esta etapa é denominada de fase de cova única, em que cada planta oriunda de uma semente é avaliada por três ciclos de produção, sendo mensurados dados sobre o ciclo, o número de frutos por cacho e a resistência à doença (Sigatoka-amarela). $\mathrm{Na}$ segunda etapa, denominada clonal, os melhores genótipos selecionados na fase única serão multiplicados e avaliados por mais dois anos, agora com cinco repetições/clones por genótipo, também em apenas um local. Por ser uma doença muito importante e necessitar de condições específicas para sua avaliação, o mal-do-panamá é avaliado em outra etapa, em área infestada com Fusarium, onde os genótipos selecionados na fase clonal são observados por dois ciclos. A etapa seguinte consiste em avaliar os genótipos selecionados como resistentes ao maldo-panamá, quanto à resistência à Sigatoka-negra. Esta etapa é realizada em Manaus (AM), devido à incidência natural do patógeno.

Por fim, os genótipos com boas características agronômicas e resistentes a essas doenças são avaliados em rede, em mais de 20 locais no Brasil (Figura 3).

\section{Perspectivas para o melhoramento de banana}

A aplicação de novas estratégias no melhoramento de plantas é altamente dependente de informações genéticas disponíveis sobre a espécie. Em bananeira, a criação de bancos de dados do genoma de Musa spp., a exemplo do DataMusa (SOUZA JÚNIOR et al., 2005), deu o passo inicial para o melhor entendimento do genoma.

$\mathrm{O}$ avanço das técnicas de Next Generation Sequencing (NGS), como a técnica de RNA-Seq (WANG et al., 2009) e os sistemas 454-Roche (BARBAZUK et al., 2007; EMRICH et al., 2007), o Illumina-Solexa (LISTER et al., 2008; MARIONI et al., 2008), e o SOLiD da Applied Biosytems (CLOONAN et al., 2008), permitem gerar grande quantidade de informações sobre genomas em curto espaço de tempo, facilitando a identificação de genes de interesse a serem usados em estratégias do melhoramento de Musa spp.

Adicionalmente, a nanotecnologia também vem ganhando espaço nesse contexto via técnica do "nanopore" (Oxford Nanopore, Pacific Biosciences, Ion Torrent) e com isso poderá facilitar e acelerar o sequenciamento de genomas a preços consideravelmente mais atrativos (EISENSTEIN, 2012).

Acredita-se que, com a recente disponibilização do genoma da DH Pahang (D'HONT et al., 2012), aliada ao baixo custo do sequenciamento genômico, haverá um salto qualitativo e quantitativo quanto a informações relevantes sobre genes candidatos envolvidos na melhoria da qualidade dos frutos, bem como na mitigação dos principais fatores bióticos e abióticos que afetam a espécie.

Portanto, a tendência é que as informações de sequências depositadas em bancos públicos de dados de genoma de Musa spp. cresça exponencialmente, não somente em nível de informação do genoma, mas também no do transcriptoma (DAVEY et al., 2009) e no do proteoma (CARPENTIER et al., 2007; SAMYN et al., 2007), acelerando o melhoramento da cultura que certamente irá beneficiar-se desse novo cenário. 


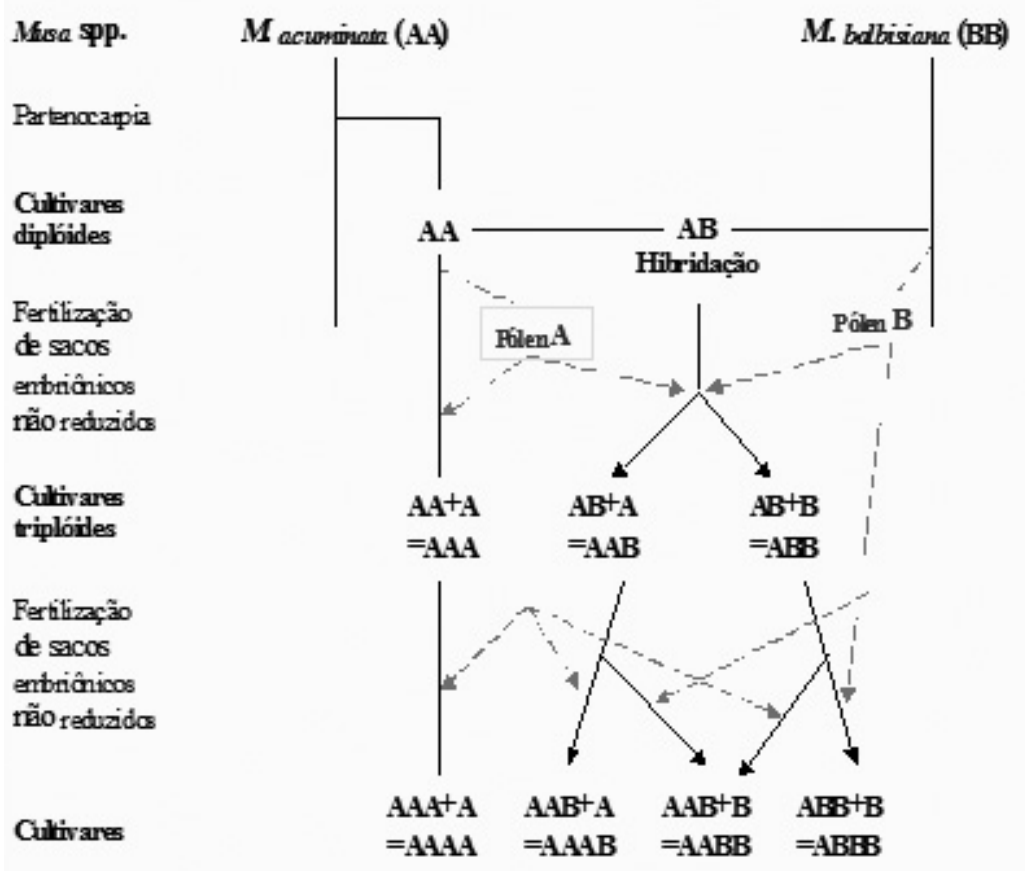

FIGURA 1- Evolução da bananeira.

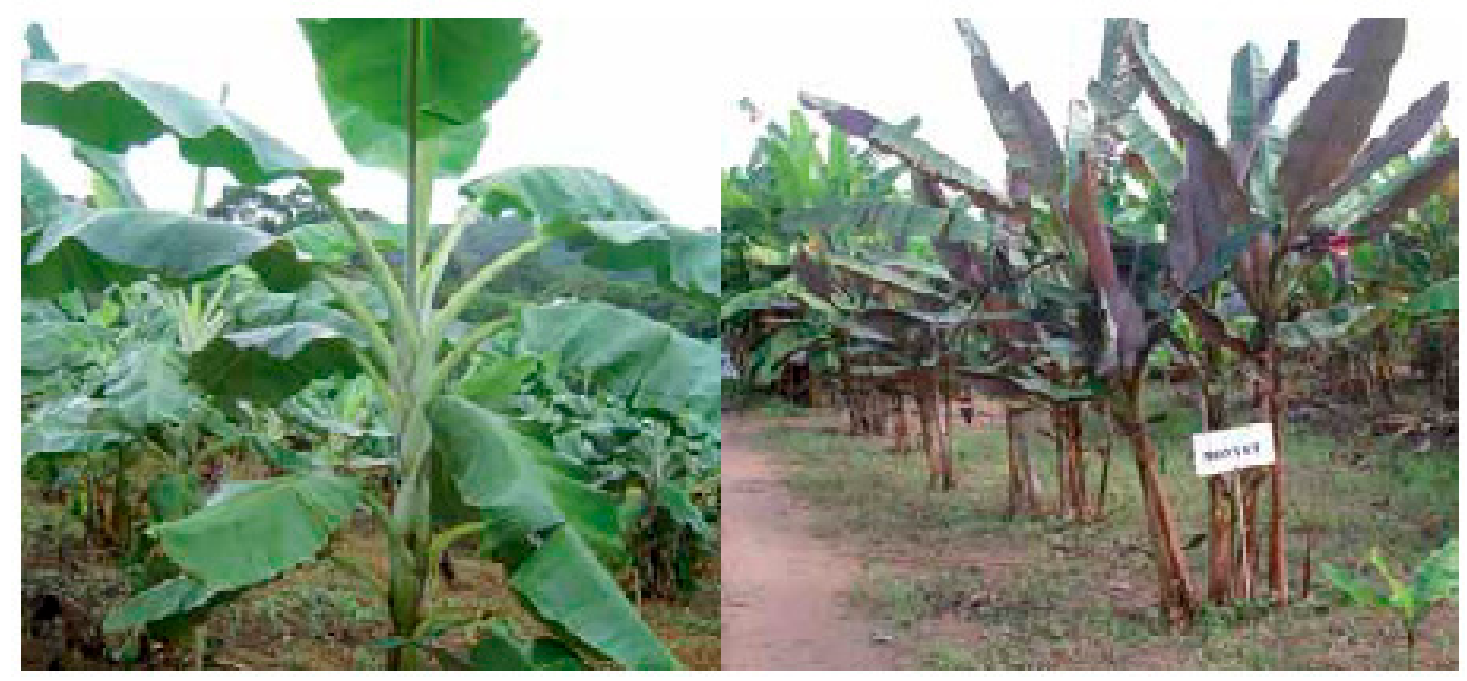

FIGURA 2 - Arquitetura de plantas tetraploides - 'Tropical'(A) comparada à das plantas diploides - Acesso Moniet (B). 


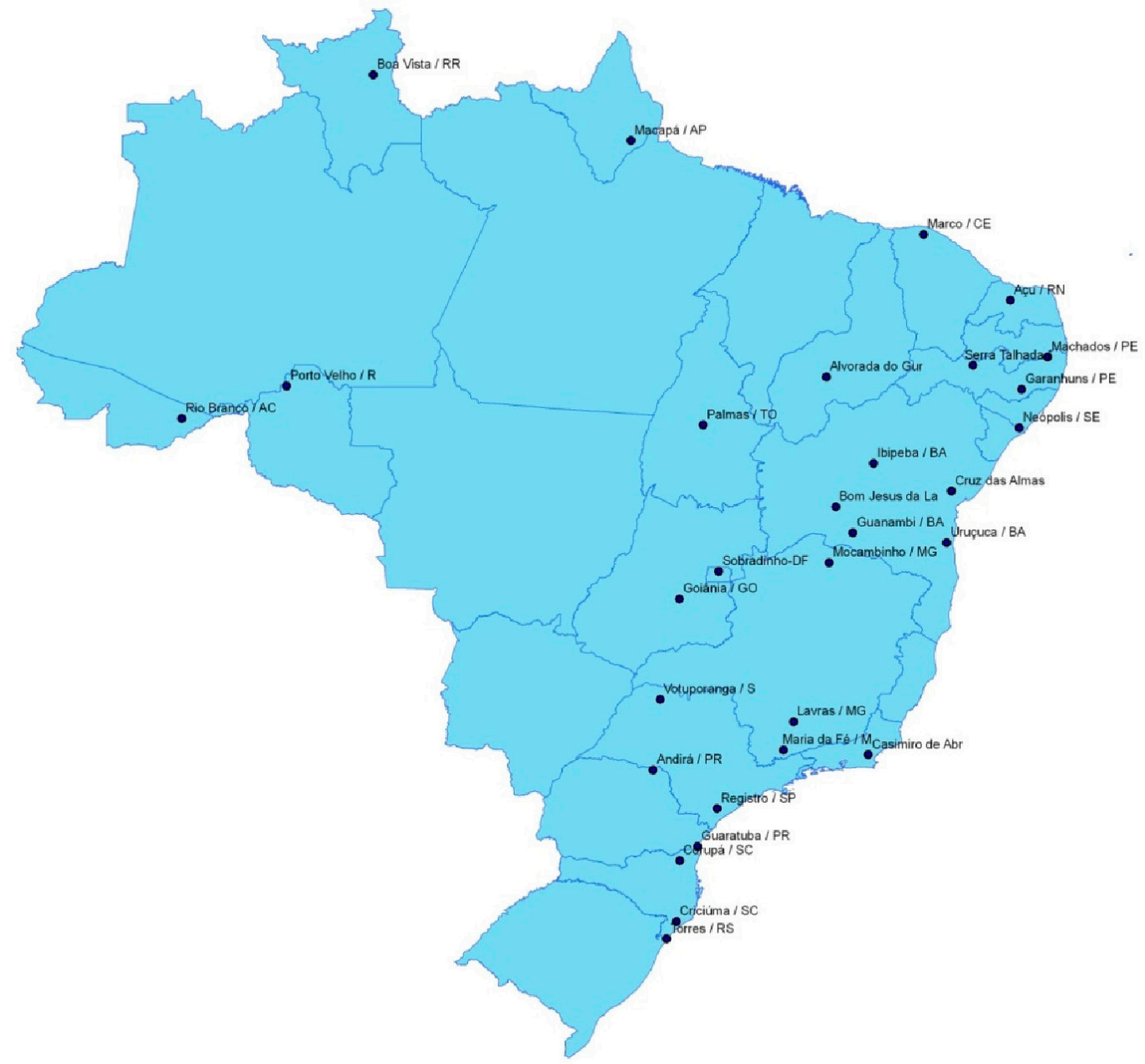

FIGURA 3 - Locais de avaliação de genótipos promissores de bananeira.

\section{REFERÊNCIAS}

AGUILAR MORÁN, J.F. Improvement of Cavendish varieties through conventional breeding. Salvador: ISHS - Embrapa, 2011. p.99-100.

ALLARD, R.W. Principles of plant breeding. $2^{\text {nd }}$ ed. New York: John Wiley, 1999. 264p.

ALVES, E. J. ; SHEPHERD, K. ; FERREIRA, F. R. Cultivares de banana caracterizadas e avaliadas no Centro Nacional de Pesquisa de Mandioca e Fruticultura. Cruz das Almas: EMBRAPA, 1985. p. 1-8. (Comunicado Técnico).

AMARAL, C. M.; SANTOS SEREJO, J. A.; SILVA, S. O. Comportamento meiótico e viabilidade de pólen em bananeira 'lidi' diploide e autotetraploide. In: CONGRESSO BRASILEIRO DE FRUTICULTURA, 22., 2012, Bento Gonçalves. Anais... Jaboticabal: SBF, 2012. CD-ROM.
AMORIM, E.P.; AMORIM, V.B.O.; SILVA, S.O.; PILLAY, M. Quality improvement of cultivated Musa. In: PILLAY, M.; TENKOUANO, A. (Org.). Banana breeding: progress and challenges. New York: CRC Press, 2011. p. 252-280.

AMORIM, E.P.; PESTANA, R.K.N.; SILVA, S.O.; TULMANN NETO, A. Caracterização agronômica de mutantes de bananeira obtidos por meio da radiação gama. Bragantia, Campinas, v.71, n.1, p. 8-14, 2012.

BAKRY, F.; CARREEL, F.; JENNY, C.; HORRY, J.P. Genetic Improvement of Banana. In: JAIN, S.M.; PRIYADARSHAN, P.M. (Org.). Breeding plantation tree crops: tropical species. New York: Springer Science, 2009. p.3-50.

BAKRY, F.; HORRY, J.P. Tetraploid hybrids from interploid $3 x \times 2 x$ crosses in cooking bananas. Fruits, Paris, v.47, p.641-647, 1992. 
BAKRY, F.; REBERDIERE, N.P.; PICHOT, S.; JENNY, C. In liquid medium colchicine treatment induces non chimerical doubled-diploids in a wide range of mono- and interspecific diploid banana clones. Fruits, Paris, v.62, p.3-12, 2007.

BARBAZUK, W. B.; EMRICH, S. J.; CHEN, H. D., Li, L. ; SCHNABLE, P. S. SNP discovery via 454 transcriptome sequencing. Plant Journal, Oxford, v.51. p.910-918, 2007.

BRIOSO, P.S.T.; CORDEIRO, Z.J.M.; REZENDE, J.A.M.; KITAJIMA,E.W.; PIMENTEL J.P.; FIGUEIREDO, A.R. Infecção mista em bananeiras pelos vírus do mosaico do pepino ("Cucumber mosaic virus" - CMV) e da risca da bananeira ("Banana streak virus"- BSV) no Brasil. Summa Phytopathologica, Botucatu, v.26, n.2, p.257-259, 2000.

BRoertjes, C.; HARTEN, A.M. van. Applied mutation breeding for vegetative propagated crops. Amsterdan: Elsevier, 1988. 500p.

BRUCKNER, C. H. Melhoramento de fruteiras. In: BORÉM, A. (Ed.). Melhoramento de espécies cultivadas. Viçosa: UFV, 1999. p.679-714.

CAPDEVILLE, G.; SOUZA JR., M.T.; SZINAY, D.; DINIZ, L.E.C.; WIJNKER, E.; SWENNEN, R.; KEMA, G.H.J.; JONG, H. The potential of high-resolution BAC-FISH in banana breeding. Euphytica, Wageningen, v. 166, p. 431-443. 2009.

CARPENTIER, S.C., WITTERS, E.; LAUKENS, K.; ONCKELEN, H.V.; SWENNEN, R.; PANIS, B. Banana (Musa spp.) as a model to study the meristem proteome: acclimation to osmotic stress. Proteomics, Weinheim, v. 7, p. 92-105, 2007.

CHAMPION, J. Les bananiers et leur culture: botanique et genetique. Paris: IFAC, 1967. v.1,214p.

CHEESMAN, E. E. Classification the bananas. III. Critical notes on species (c) $M$. paradisiaca, $M$. sapientum. Kew Bulletin, London, v. 2, p. 147-153, 1948.

CHEESMAN, E.E.; DODDS, K.S. Genetical and cytological studies of Musa. IV. Certain triploid clones. Journal of Genetics, Bangalore, v.43, p.337357, 1942.

CLOONAN, N. et al. Stem cell transcriptome profiling via massive-scale mRNA sequencing. Nature Methods, New York, v.5, p.613-619, 2008.
COSTA, F.H.S.; PASQUAL, M.; SILVA, S.O.; NETO, H.P.S.; AMORIM, E.P.; SANTOS-SEREJO, J.A. Poliploidização em ápices caulinares de bananeira e seus efeitos morfofisiológicos in vitro. Pesquisa Agropecuária Brasileira, Brasília, v.46, p.805-813, 2011.

CÔTE, F.X.; SANDOVAL, J.A.; MARIE, P.H.; AUBOIRON, E. Variations in micropropagated bananas and plantains: literature survey. Fruits, Paris, v.48, p.11-18, 1993.

D'HONT, A. et al. The banana (Musa acuminata) genome and the evolution of monocotyledonous plants. Nature, London, 2012. Disponível em: $<$ http://www.nature.com/nature/journal/v488/n7410/ pdf/nature11241.pdf $>$. Acesso em: dia mes ano.

D'HONT, A.; PAGET-GOY, A.; ESCOUTE, J.; CARREL,F. The interespecific genome structure of cultivated banana, Musa spp. Revealed by genomic DNA in situ hybridization. Theoretical Applied Genetics, Berlin, v.100, p.177-183, 2000.

DANTAS, J.L.L.; SHEPHERD, K.; SILVA, S.O.; SOARES FILHO, W.S. Classificação botânica, origem, evolução e distribuição geográfica. In: ALVES, E.J. (Org.). A cultura da banana, aspectos técnicos sócioeconômicos e agroindustriais. Brasília: EMBRAPA-SPI; 1997. p 27-34.

DAVEY, M.W.; KEULEMANS, J.; GRAHAM, N.; MAY, S.T.; VANHOLME B.; SWENNEN, R. Assessing the use of heterologus oligonucleotide microarrays for transciptomics in a non-model species; application to the study of drought stress in Musa. Acta Horticulturae, Wageningen, n.839, p.607-614, 2009.

DODDS, K.S. Genetical and cytological studies of Musa. VI. The development of female cells of certain edible diploids. Journal of Genetics, Bangalore, v.46, p.161-179, 1945.

DODDS, K.S.; PITTENDRIGH, C.S. Genetical and cytological studies of Musa. VII. Certain aspects of polyploidy. Journal of Genetics, Bangalore, v.47, p.162-177, 1946.

DODDS, K.S.; SIMMONDS, N.W. Genetical and cytological studies of Musa. VIII. The formation of polyploid spores. Journal of Genetics, Bangalore,v.47, p.223-241, 1946. 
DOLEZEL J.; BARTOS J. Plant DNA flow cytometry and estimation of nuclear genome size. Annals of Botany, London, v.95, p.99-110. 2005.

EISENSTEIN, M. Oxford Nanopore announcement sets sequencing sector abuzz Nature Biotechnology, Frankfurt, v.30 p.295-296,.2012.

EMRICH，S. J.;BARBAZUK, W. B.; Li，L; SCHNABLE, P. S. Gene discovery and annotation using LCM-454 transcriptome sequencing. Genome Research, New York, v.17, p.69-73, 2007.

FAO. Food and Agriculture Organization of the United Nations. Disponível em: $<$ http://www.faostat. fao.org/site/340/default.aspx>. Acesso em: 6 ago. 2012.

FAO/IAEA. Mutant variety search. 2012. Disponível em: $<$ http://mvgs.iaea.org/Search.aspx/>. Acesso em: 8 ago. 2012.

HORRY, J.P.; BAKRY, F.; GANRY, J. Creation of varieties through hybridization of diploids. In: GANRY, J. (Ed.). Breeding banana and plantain for resistance to diseases and pests. Montpellier. CIRAD-FLHOR, 1993. p. 293-299.

HWANG S-C. Cavendish banana cultivars resistant to fusarium wilt acquired through somaclonal variation in Taiwan. Plant Disease, Saint Paul, v.88, p.580-588, 2004.

ISRAELI, Y.; LAHAV, E.; REUVENI, O. In vitro culture of bananas. In: GOWEN, S. (Ed.). Bananas and plantains. London: Chapman and Hall, 1995. p.147-178.

JAIN, S.M. A review of induction of mutations in fruits of tropical and subtropical regions. Acta Horticulturae, Wageningen, v.575, p.295-302, 2002.

KHAYAT, E.; DUVDEVANI, A.; SHCHUKIN, A.; LAVAH, E. Banana improvement program at Rahan meristem. Acta Horticulturae, Wageningen, n.490, p.71-78, 1998.

KHAYAT, E.; ORTIZ, R. Genetic of important traits in Musa. In: PILLAY, M.; TENKOUANO, A. (Org.). Banana breeding: progress and challenges. New York: CRC Press, 2011.p. 71-83.
KOVÁCS, G.; SÁGI, L.; JACON, G.; ARINAITWE, G.; BUSOGORO, J.P.; THIRY, E.; STROSSE, H.; SWENNEN, R.;REMY, S. Expression of a rice chitinase gene in transgenic banana ('gros michel', aaa genome group) confers resistance to black leaf streak disease.Transgenic Research, London, v.22. n.1, p.117-130, 2013.

\section{LICHTEMBERG, L.A. Bananicultura nos subtrópicos. Itajaí: Epagri/EEI, 1997. 48p.}

LISTER, R.; O'MALLEY, R.C.; TONTIFILLIPPINI, J.; GREGORY, B.F.; BERRY,C.C.; MILLAR, A. H.; ECKER, J.R. Highly integrated single-base resolution maps of the epigenome in Arabidopsis. Cell, Cambridge, v.133, p.523-536, 2008.

MARIONI, J.; MASON, C.; MANE, S.; STEPHENS, M.; GILAD, Y. RNA-seq: an assessment of technical reproducibility and comparison with gene expression arrays. Genome Research, New York, v.11. 2008.

MENENDEZ, T.; SHEPHERD, K. Breeding new bananas. World Crops, London, p.104-112, 1975.

MORAIS-LINO, L.S.; Amaral, C. M ; AMORIM, E. P.; SANTOS-SEREJO, J. A.; SILVA, S. O. e ; PIO, L. A. S. Morphological Characterization and Fertility of Auto-Tetraploid Bananas Obtained by Chromosome Doubling. In: PROMUSA: BANANAS AND PLANTINS, 2011, Salvador, 2011. p.136-136.

NEWBURY, H.J.; HOWELL, E.C.; CROUCH, J.H.; FORD-LLOYD, B.V. Natural and culture-induced genetic variation in plantains (Musa spp., AAAB group). Australian Journal of Botany, Melbourne, v.48, p.493-500, 2000.

NOVAK, F. J.; BRUNNER, H.; AFZA, R.; PHADVIBULYA, V.; HERMELIN, T.; DONNI, B. Micropropagation and radiation sensitivity in shoot tip cultures of banana and plantain. In: IAEA. Nuclear technics and in vitro culture for plant improvement. Vienna, 1986. p.167-174.

NOVAK, F.J.; AFZA, R.;. DUREN, M.V.; OMAR, M.S., Mutation Induction by gamma irradiation of in vitro cultured shoot-tips of banana and plantain (Musa sp.). Tropical Agriculture, Surrey, v.67, p.21-28,1990. 
OSELEBE, H.O.; TENKOUANO, A.; PILLAY, M. Ploidy variation of Musa hybrids from crosses. African Journal of Biotechnology, Nairobi, v.5, p.1048-1053, 2006.

OSUJI, J.O.; HARRISON, G.; CROUCH, J.; HESLOP-HARRISON, J. S. Identification of genomic constitution of Musa L. lines (bananas, plantains and hybrids) using molecular cytogenetics. Annals of Botany, London, v. 80, p. 787-793, 1997.

PERRIER, X.; BAKRY, F.; CARREEL, F. et al. Combining biological approaches to shed light on the evolution of edible bananas. Ethnobotany Research and Applications, Fort Worth, v.7, p.199-216, 2009.

PERRIER, X. et al. Multidiciplinary perspectives on banana (Musa spp.) domestication. Proceedings of the National Academy of Sciences of USA, Washington, v.108, n.28, p.1311-1318, 2011.

PESTANA, R.K.N.; AMORIM, E.P.; FERREIRA, C.F.; AMORIM, V.B.O.; OLIVEIRA, L.S.; LEDO, C.A.S.; SILVA, S.O. Genetic dissimilarity of putative gamma-ray-induced 'Preciosa' - AAAB-Pome type banana (Musa sp.) mutants based on multivariate statistical analysis. Genetics and Molecular Research, Ribeirão Preto, v. 10, p. 3.976-3.986, 2011a.

PESTANA, R.K.N.; AMORIM, E.P.; FERREIRA, C.F.; AMORIM, V.B.O.; OLIVEIRA, L.S.; LEDO, C.A.S.; SILVA, S.O. Agronomic and molecular characterization of gamma ray induced banana ( $M u s a$ sp.) mutants using a multivariate statistical algorithm. Euphytica, Wageningen, v. 178, p. 151-158, 2011 b.

PILLAY, M.; ASHOKKUMAR, K.; SHUNMUGAM, A.S.K.; ELAYABALAM, S. A case for molecular breeding in Musa. In: PILLAY, M.; UDE, B.; KOLE, C. (Ed.). Genetics, genomis and breeding of bananas. Enfield: Science Publisher, 2012. p.281-297.

PREDIERI, S. Mutation induction and tissue culture in improving fruits. Plant Cell, Tissue and Organ Culture, Dordrecht, v.64, p.185-210, 2001.

PUA, E.C.; LEE, Y.C. Expression of a ripeningrelated cytochrome $\mathrm{P} 450 \mathrm{cDNA}$ in Cavendish banana (Musa acuminata cv. Williams). Gene, Amsterdam, v. 305, p. 133-140, 2003.
RAMALHO, M.A.P.; SANTOS, J.B.; PINTO, C.A.B.P.; SOUZA, E.A.; GONÇALVES, F.M.A.; SOUZA, J.B. Genética na agropecuária. Lavras: Ed. UFLA, 2012. 566p.

REMY, S.; SANTOS, E.; THIRY, E.; WINDELINCKX, S.; SWENNEN, R.; SÁGI, L. Genome-wide T-DNa tagging in banana. In: CONFERENCE PLANT AND ANIMAL GENOMES, 15., San Diego, 2007. Proceedings...

ROWE, P.R.; ROSALES, F.E. Current approaches and future opportunities for improving Gros Michel (AAA Desert) Bananas. In: FRISON, E.A.; HORRY, J.P.; WAELE, D. DE. New frontiers in resistance breeding for nematode fusarium and sigatoka. Montpellier: IPGRI/CIRAD/MARDI/INIBAP, 1995. p.119-122.

ROWE, P. R.; ROSALES, F.E.; JANICK J.; MOORE, J.N. (Ed.). Bananas and plantains. London: John Wiley, 1996. p167-211.

SALA, F.; RIGANO, M.M.; BARBANTE, A.; BASSO, B.; WALMSLEY, A.M.; CASTIGLIONE, A.M. Vaccine antigen production in transgenic plants: strategies, gene constructs and perspectives. Vaccine, Kidlinton, v.21, p.803-808, 2003.

SAMYN, B.; SERGEANT, K.; CARPENTIER, S.; DEBYSER, G.; PANIS, B.; SWENNEN, R.; BEEUMEN, JV. Functional proteome analysis of the banana plant (Musa spp.) using de Novo sequence analysis of derivatized peptides. Journal of Proteome Research, Washington, v. 6, p.70-80, 2007.

SCHIFINO-WITTMANN, M.T.; DALL'AGNOL, M. Gametas não reduzidos no melhoramento de plantas. Ciência Rural, Santa Maria, v.31, p. 169$175,2001$.

SHEPHERD, K. Banana germplasm. Roma: IBPGR, 1976. 7p.

SHEPHERD, K. Banana research at I.C.T.A. Tropical Agriculture, Surrey, v.51, p.485-489, 1974.

SHEPHERD, K. Banana: taxonomia e morfologia. In: SIMPÓSIO BRASILEIRO SOBRE BANANICULTURA, 1., 1984, Jaboticabal. Anais... Jaboticabal: FCAVJ/UNESP, 1984. p. 50-74. 